(c) 2019 Universidad Nacional Autónoma de México, Facultad de Estudios Superiores Zaragoza.

Este es un artículo Open Access bajo la licencia CC BY-NC-ND (http://creativecommons.org/licenses/by-nc-nd/4.0/).

TIP Revista Especializada en Ciencias Químico-Biológicas, 22: 1-10, 2019.

DOI: 10.22201/fesz.23958723e.2018.0.163

\title{
Microdominios membranales bacterianos semejantes a balsas lipídicas
}

\author{
José E. Guzmán-Flores ${ }^{1}$, Dimitris Georgellis ${ }^{1}$ y Adrián F. Álvarez ${ }^{1 *}$ \\ ${ }^{1}$ Departamento de Genética Molecular, Instituto de Fisiología Celular, Universidad Nacional \\ Autónoma de México, Ciudad de México, 04510, México. *E-mail: aalvarez@ifc.unam.mx
}

\begin{abstract}
RESUMEN
La capacidad de las membranas biológicas para compartimentar diversos procesos fisiológicos como la transducción de señales, tráfico vesicular, entre otros, ha llevado al estudio de estructuras conocidas como balsas lipídicas o microdominios de membrana. Estos microdominios se componen de proteínas y lípidos especializados, los cuales han sido ampliamente descritos en una gran variedad de células eucariotas. Una característica de las balsas lipídicas es el alto grado de empaquetamiento de sus componentes, lo que genera una menor fluidez con respecto al resto de la membrana. La técnica más empleada para caracterizar estos microdominios, es la generación de membranas

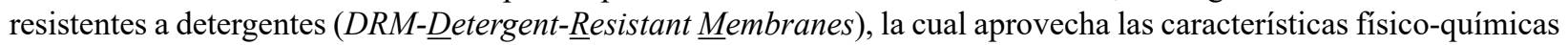
de las balsas lipídicas, cuyos componentes estructurales son resistentes a la solubilización por detergentes. Las proteínas que contienen un dominio conocido como SPFH (ㅁtomatin, Prohibitin, Flotillin, $\underline{H} f 1 K / C$ ) son consideradas como marcadores de balsas lipídicas y se identifican frecuentemente en preparaciones de DRM. Recientemente, la amplia distribución de proteínas con dominios SPFH codificadas en cromosomas bacterianos, ha dirigido el enfoque al estudio de estructuras similares a balsas lipídicas en las membranas bacterianas. En esta revisión se exponen algunos avances recientes en la identificación y estudio de los microdominios de membrana bacterianos similares a balsas lipídicas presentes en eucariontes.
\end{abstract}

Palabras Clave: bacteria, balsas lipídicas, membranas resistentes a detergentes, flotilina.

\section{Lipid raft-like bacterial membrane microdomains}

\begin{abstract}
The capacity of biological membranes to compartmentalize various physiological processes such as signal transduction, vesicular traffic, among others, has led to the study of structures known as lipid rafts or membrane microdomains. These microdomains are made of specialized proteins and lipids, which have been widely described in a broad variety of eukaryotic cells. A feature of lipid rafts is the high degree of packaging of their components, which generates less fluidity with respect to the rest of the membrane. The most commonly used technique to characterize these microdomains is the generation of Detergent-Resistant Membranes (DRM), which takes advantage of the physicochemical characteristics of lipid rafts, whose structural components are resistant to solubilization by detergents. SPFHdomain containing proteins (Stomatin, Prohibitin, Flotillin, HflK/C) are frequently found in DRM preparations and are commonly used as lipid rafts markers. Recently, the widely distribution of SPHF-containing proteins encoded in bacterial chromosomes, has directed our attention to the study of lipid raft-like microdomains in bacterial membranes. In this review, we present some recent advances on the identification and analysis of bacterial lipid raft-like membrane microdomains.
\end{abstract}

Key words: bacteria, lipid rafts, detergent-resistant membranes, flotillin.

Nota: Artículo recibido el 29 de octubre del 2018 y aceptado el 07 de febrero del 2019. 


\section{INTRODUCCIÓN}

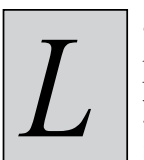

as membranas biológicas están constituidas principalmente por lípidos de naturaleza anfipática y proteínas asociadas que forman una barrera semipermeable que delimita el interior y el exterior de la célula. Una de las familias de lípidos más abundantes en las membranas la constituyen los glicerofosfolípidos, los cuales contienen dos ácidos grasos unidos a un esqueleto de glicerol, un grupo fosfato y una cabeza polar variable que determina el tipo de glicerofosfolípido. Algunos glicerofosfolípidos que destacan en la composición de las membranas bacterianas son: la fosfatidiletanolamina (PE), el fosfatidilglicerol (PG), la cardiolipina (CL), el lisil-fosfatidil-glicerol (LPG), el fosfatidilinositol (PI), el ácido fosfatídico (PA) y la fosfatidilserina (PS). Además de los lípidos anteriormente mencionados, las bacterias son capaces de formar otros lípidos libres de fósforo como: los lípidos de ornitina (OL), los sulfolípidos, el diacilgliceril-N,N,N-trimetilhomoserina (DGTS), los glicolípidos (GL), el diacilglicerol (DAG), los hopanoides (HOP), entre otros (Sohlenkamp \& Geiger, 2016).

Desde hace más de 100 años, la tinción de Gram ha permitido clasificar a las bacterias en dos grandes grupos, según las características y composición de la envoltura celular, que determina la capacidad de retener el colorante cristal violeta. Posteriormente, la microscopía electrónica permitió poner en evidencia las diferencias morfológicas de las bacterias Gram negativas y Gram positivas. En las bacterias Gram positivas se pueden identificar dos estructuras que envuelven a la bacteria: la pared celular (compuesta por peptidoglicano) y la membrana citoplásmica o membrana interna (MI). Por otro lado, en las bacterias Gram negativas, adicionalmente a la MI y a la pared celular, existe una membrana externa (ME) que recubre a las células (Silhavy, Kahne, \& Walker, 2010). Existen diferencias significativas en la composición de estas estructuras membranales, mientras que la cara interna de la ME está compuesta de fosfolípidos (PL), la cara externa es rica en glucolípidos, principalmente lipopolisacáridos (LPS) (Kamio \& Nikaido, 1976). Por otro lado, la MI está compuesta mayoritariamente por los glicerofosfolípidos anteriormente mencionados, y también se ha observado que existe asimetría en la distribución de lípidos entre las caras de la bicapa lipídica, habiendo mayor cantidad de PE en la cara interna y de PG en la cara externa (Rothman \& Kennedy, 1977). Además, la CL se distribuye predominantemente en los polos de las bacterias de tipo bacilar. Esta distribución preferente de la CL en las regiones cóncavas del bacilo es consistente con la forma cónica predicha de una molécula de CL (debido a una cabeza polar relativamente pequeña en comparación a la porción hidrofóbica), que le permite localizarse en las regiones con curvatura negativa (Renner \& Weibel, 2011).

La distribución y presencia de los lípidos difiere notablemente entre géneros y especies bacterianas. Por ejemplo, en
Escherichia coli la PE representa cerca del 75\% del porcentaje total de lípidos, y el PG y la CL representan el 15\% y 5\% respectivamente(Cronan, 2003), mientras que en Pseudomonas aeruginosa, los porcentajes de PE, PG y CL corresponden al $60 \%, 21 \%$ y $11 \%$ respectivamente (Gilleland \& Lyle, 1979). En otro ejemplo, en Bacillus subtilis el porcentaje de PE, PG y CL es de $12 \%, 70 \%$ y $4 \%$ respectivamente; además de presentar otros lípidos como los GL (5\%), DAG (2\%), entre otros (Clejan, Krulwich, Mondrus, \& Seto-Young, 1986). Es importante destacar, que la composición de la membrana de $E$. coli es relativamente simple y no es representativa de la gran variedad de lípidos que pueden contener las membranas bacterianas.

Por otra parte, las proteínas también constituyen un componente mayoritario en las membranas bacterianas. Estudios por predicción de localización por secuencia han determinado que cerca del 20-30\% de los genomas bacterianos codifican para proteínas integrales de membrana (Krogh, Larsson, von Heijne, \& Sonnhammer, 2001). En el caso de E. coli, se ha predicho que cerca de 1,000 del total de 4,288 genes codifican para alguna proteína integral y que poseen al menos un cruce transmembranal (TM) (Daley et al., 2005; Krogh, Larsson, von Heijne \& Sonnhammer, 2001). Sin embargo, algunas lipoproteínas, así como proteínas solubles citosólicas (que no poseen TM), pueden ser reclutadas en la membrana según la demanda de diversos procesos celulares (Luirink, Yu, Wagner, \& de Gier, 2012; Papanastasiou et al., 2013).

\section{ORGANIZACIÓN DE LAS MEMBRANAS BIOLÓGICAS}

A lo largo de la historia diversos modelos han tratado de explicar la naturaleza, composición y distribución de las membranas biológicas. El modelo del mosaico fluido marcó un paradigma en el estudio de las mismas (Singer \& Nicolson, 1972), al reconocer que las proteínas anfipáticas residen dentro de la bicapa lipídica y poseen una estructura dinámica, asumiendo una distribución homogénea de los componentes a lo largo de la membrana. En esa época, diversos estudios corroboraron la capacidad de los componentes de la membrana de transportarse lateralmente (Frye \& Edidin, 1970).

Durante mucho tiempo se mantuvo el paradigma respecto a la distribución homogénea de los componentes de las membranas, como lo sugería el modelo del mosaico fluido. Sin embargo, estudios en células eucariontes sobre el tráfico de lípidos y transducción de señales, sugirieron que tanto los lípidos como las proteínas de membrana no se localizan aleatoriamente en la bicapa lipídica (Lisanti \& RodríguezBoulan, 1990). En bacterias, a través de diversas técnicas de tinción de lípidos, se han observado regiones específicas en la membrana cuya composición lipídica difiere con el resto de la bicapa. Por ejemplo, en $E$. coli se han puesto en evidencia porciones de la membrana enriquecidas en $\mathrm{PE}$, así como otras con una mezcla compuesta de PG y CL (Fishov \& 
Woldringh, 1999). Adicionalmente, se ha definido que la CL se enriquece principalmente en los polos y el septo de la célula en división en géneros y especies bacterianas diversas como E. coli (Mileykovskaya \& Dowhan, 2000), Pseudomonas putida (Bernal, Muñoz-Rojas, Hurtado, Ramos, \& Segura, 2007), Bacillus subtilis (Kawai et al., 2004) y Mycobacterium tuberculosis (Maloney et al., 2011).

En un medio acuoso, los lípidos que constituyen a las membranas biológicas pueden existir en diferentes estados físicos de acuerdo con su organización lateral, el grado de ordenamiento y la movilidad de las moléculas lipídicas. Estos diversos estados ocasionan numerosos re-arreglos espaciales y grados de libertad de cada lípido con respecto a sus vecinos, por lo que diversas fases pueden coexistir a lo largo de la membrana. El tipo de fase adoptada depende de la estructura de los lípidos como longitud y saturación de las cadenas hidrocarbonadas, aunque otros parámetros fisicoquímicos como la temperatura, $\mathrm{pH}$, fuerza iónica pueden afectar la naturaleza de las fases. Los dos extremos de los estados de los lípidos son la fase sólido-gel y la líquida (van Meer, Voelker, \& Feigenson, 2008). Además, se ha descrito que tanto las proteínas solubles como las asociadas a la membrana pueden interactuar con lípidos específicos o dominios de lípidos y de esta manera afectar a las propiedades globales de la bicapa lipídica (Deol, Bond, Domene, \& Sansom, 2004; Lee, 2003).

En la fase sólido-gel $\left(\mathrm{L}_{\beta}\right)$ o también llamada sólido ordenado $\left(\mathrm{s}_{\mathrm{o}}\right)$, las cadenas hidrocarbonadas de los lípidos muestran una configuración saturada y con alargamiento máximo, dando como resultado una red de lípidos extremadamente compacta y altamente ordenada (S) (Figura 1a); en consecuencia, la difusión lateral de los lípidos $\left(\mathrm{C}_{\mathrm{T}}\right)$ está fuertemente disminuida. Mientras que en la fase fluida $\left(\mathrm{L}_{\alpha}\right)$ o también llamada líquido desordenado $\left(l_{d}\right)$, las cadenas hidrocarbonadas son generalmente insaturadas y menos extendidas (Figura 1b), por lo que la red de lípidos es laxa y poco ordenada, resultando en una $\mathrm{C}_{\mathrm{T}} \mathrm{y}$ difusión rotacional de los lípidos alta. Debido a lo anterior, pueden existir diferentes grados de fluidez a lo largo de la membrana de acuerdo a la composición de la misma (Siontorou, Nikoleli, Nikolelis, \& Karapetis, 2017; van Meer, Voelkner \& Feigenson, 2008). Los esteroles, que se encuentran principalmente en las membranas biológicas de eucariontes, no son capaces por sí mismos de generar bicapas lipídicas. Sin embargo, cuando estos se intercalan en bicapas ya formadas pueden generar fases de líquido ordenado $\left(1_{\mathrm{o}}\right)$ que tienen características tanto de la fase sólido-gel como la líquida (Figura 1c); esta fase es altamente ordenada, además los valores de $\mathrm{C}_{\mathrm{T}} \mathrm{y}$ velocidad de difusión lateral son casi tan altos como en la fase $1_{d}$ pero mantienen grados de fluidez menores como en fase $\mathrm{s}_{\mathrm{o}}$ (van Meer, Voelkner \& Feigenson, 2008). Interesantemente, la mayoría de las membranas bacterianas carecen de esteroles en su membrana.

\section{DOMINIOS DE MEMBRANA: BALSAS LIPÍDICAS}

Una consecuencia de los múltiples estados de fluidez de la membrana es que los componentes que conforman la fase $l_{0}$ pueden estar organizados en una distribución heterogénea, provocando la creación de plataformas o dominios que difieren en composición de lípidos y proteínas con respecto del resto de la membrana. La presencia de estos dominios de membrana es evidente en algunos tipos de células eucariontes polarizadas. Por ejemplo, existen dominios en la membrana basolateral y apical de las células epiteliales los cuales se extienden por varios micrómetros. Aunque morfológicamente parecidos, estos dos dominios membranales tienen funciones específicas dependiendo de la línea celular (Mazzone, Tietz, Jefferson, Pagano, \& LaRusso, 2006; Simons \& Van Meer, 1988; Stoops \& Caplan, 2014). Los primeros intentos por explicar las diferencias en la organización de la membrana plasmática,
A

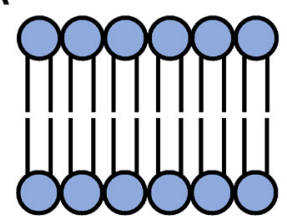

Sólido ordenado

$s_{o}\left(L_{\beta}\right)$

$\mathrm{S}=$ Alto

$C_{\mathrm{T}}=$ Lento $\left(10^{-3} \mu \mathrm{m}^{2} \mathrm{~s}^{-1}\right)$
B

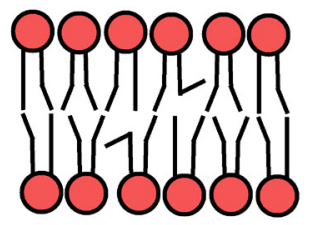

Líquido desordenado

$I_{d}\left(L_{a}\right)$

$\mathrm{S}=$ Bajo

$\mathrm{C}_{\mathrm{T}}=$ Rápido $\left(\sim 1 \mu \mathrm{m}^{2} \mathrm{~s}^{-1}\right)$
C

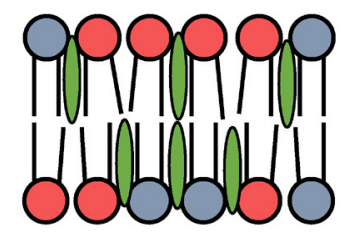

Líquido ordenado

$I_{0}\left(L_{0}\right)$

$\mathrm{S}=$ Alto

$\mathrm{C}_{\mathrm{T}}=$ Rápido $\left(\sim 1 \mu \mathrm{m}^{2} \mathrm{~s}^{-1}\right)$
I Fosfolípidos saturados

R Fosfolípidos insaturados

Esteroles

Figura 1. Tipos de fase de membrana y características relevantes. a) Sólido ordenado ( $\left.s_{0}\right)$, las cadenas de los ácidos grasos se encuentran insaturadas generando un estado sólido con características de fluidez reducida y alto grado de ordenamiento. b) Líquido desordenado $\left(l_{d}\right)$, las cabezas polares de los fosfolípidos pueden rotar libremente permitiendo una fluidez alta pero un grado de ordenamiento menor. c) Líquido ordenado $\left(l_{0}\right)$ las cadenas aciladas de los fosfolípidos se encuentran estabilizadas por esteroles u otros lípidos permitiendo un alto grado de ordenamiento por lo que su fluidez se reduce considerablemente, pero mantiene la velocidad de difusión lateral como en la fase $l_{d}$. $\mathrm{S}$ : entropía, $\mathrm{C}_{\mathrm{T}}$ : coeficiente de difusión lateral de lípidos. Fuente: elaboración propia. 
además de la localización de lípidos y proteínas, condujeron a la propuesta de que pequeñas áreas en la membrana se encontraban en fase 1 , por lo que permanecían "flotando" en superficies más grandes de fases $1_{\mathrm{d}}$, haciendo una analogía: "parecidas a las balsas en agua" (Brown \& Rose, 1992; Simons \& Van Meer, 1988). Los reportes de Simons \& Ikonen (1997), propusieron que existen microdominios de membrana en células epiteliales polarizadas, los cuales contienen diferentes composiciones de lípidos y grados de fluidez a lo largo de la membrana, a los que llamaron "balsas lipídicas". Desde que surgió este concepto, la definición de balsa lipídica ha ido cambiando a lo largo de los años, hasta que en el Keystone Symposium on Lipid Rafts and Cell Function, celebrado en 2006, se logró establecer una definición consenso. Según la definición, la balsa lipídica debe ser pequeña (10-220nm), heterogénea, altamente dinámica, enriquecida en esteroles y esfingolípidos, además de compartimentar procesos celulares y ser estabilizadas por interacciones proteína-proteína y proteína-lípido (Pike, 2006). Si bien esta definición describe de manera completa a los microdominios de membrana de células eucariotas, descarta la posibilidad de que las membranas bacterianas contengan balsas lipídicas, ya que la gran mayoría de las bacterias carecen de esteroles y esfingolípidos en sus membranas. Sin embargo recientemente, a través de diversas técnicas y enfoques, se han identificado dominios membranales similares a las balsas lipídicas en diversos géneros bacterianos como: E. coli (Guzmán-Flores, Álvarez, Poggio, Gavilanes-Ruiz, \& Georgellis, 2017; López \& Kolter, 2010), Staphylococcus aureus (López \& Kolter, 2010), Bacillus anthracis (Somani, Aggarwal, Singh, Prasad, \& Bhatnagar, 2016), Bacteroides fragilis (An, Na, Bielawski, Hannun, \& Kasper, 2011), Borrelia burgdorferi (LaRocca et al., 2013) y Helicobacter pylori (Hutton et al., 2017).

\section{Membranas resistentes a Detergentes}

La herramienta más empleada para el estudio de la composición de dominios membranales es la extracción por detergentes no iónicos como el Tritón X-100. La técnica se basa en las propiedades físico-químicas que le permiten a la membrana mantener o perder su composición y estructura por tratamientos con detergentes. Esto se debe a que el tratamiento con detergentes puede afectar a la mayoría de las interacciones lípido-lípido de la membrana biológica, sin embargo, una pequeña porción de la membrana es capaz de resistir al tratamiento con detergentes y puede recuperarse como DRM (membranas resistentes a detergentes, acrónimo del inglés Detergent-Resistant Membranes) (Brown, 2006) (Figura 2a). Se ha sugerido que los DRM preparados con Tritón X-100, posiblemente se originan al extraer la fase $1_{o}$ de la membrana debido al alto empaquetamiento de los lípidos (Brown \& London, 1998). También, la extracción por detergente es capaz de alterar las interacciones lípido-proteína, de tal manera que gran parte de las proteínas de membrana se solubilizan. Por otro lado, sólo algunas proteínas conservan su asociación con los lípidos y pueden recuperarse en DRM. La asociación de una proteína-lípido en forma de DRM puede indicar una fuerte interacción de la proteína con los dominios de fase $1_{\mathrm{o}}$ (Brown \& London, 1998). Por lo tanto, uno de los primeros métodos para la caracterización bioquímica de las balsas lipídicas fue el análisis de las fracciones enriquecidas en DRM.

Los DRM han sido ampliamente caracterizados en células eucariontes y usualmente son preparados con los detergentes Tritón X-100 (Brown \& Rose, 1992) y CHAPS (Alfalah et al., 2005). Sin embargo, también se ha documentado el uso de otros detergentes como Brij 58 y 98 (Williamson et al., 2010), Lubrol WX (Delaunay, Breton, Trugnan, \& Maurice, 2008), incluso se han reportado preparaciones libres de detergentes empleando carbonato de sodio (Macdonald \& Pike, 2005). Sin embargo, existen evidencias en modelos eucariontes de que las proteínas enriquecidas en las fracciones de DRM pueden variar de acuerdo con el detergente empleado para solubilizar a la membrana. Un ejemplo es el receptor de transferrina, el cual se enriquece cuando se usa Tritón X-100 y CHAPS pero se solubiliza al usar Brij 98, Brij 96, Brij 58, Lubrol WX y Tween 20 (Schuck, Honsho, Ekroos, Shevchenko \& Simons, 2003).

La solubilización empleando $1 \%$ de Tritón $\mathrm{X}-100$ a $4^{\circ} \mathrm{C}$, suele ser usada en diversas preparaciones debido al mayor rendimiento al recolectar las fracciones enriquecidas en DRM. Ya que existe una relación alta de lípido/proteínas, los DRM poseen una baja densidad y pueden ser recuperados en gradientes de sacarosa u Optiprep (Figura 2b). Frecuentemente pueden ser recuperados en la interfaz correspondiente entre 5\%-30\% del gradiente (Babiychuk \& Draeger, 2006; Magee \& Parmryd, 2003; Nebl et al., 2002). Otro parámetro crítico para el aislamiento de los DRM es la selección adecuada de la proporción detergente/proteína membranal, que debe adaptarse según la naturaleza de la membrana biológica (Schuck, Honsho, Ekroos, Shevchenko \& Simons, 2003). Por ejemplo, existen reportes en donde se usa una relación detergente/proteína 15:1 para la preparación de DRM de hojas de Nicotiana tabacum (Mongrand et al., 2004), por otro lado, se ha reportado una proporción de 8:1 para preparaciones similares en hojas de Arabidopsis thaliana (Borner et al., 2005). Además, se informó una relación de 12.5:1 como la condición óptima para las preparaciones de DRM a partir de membranas plasmáticas de Phaseolus vulgaris, hojas de Nicotiana tabacum y germinación de embriones de Zea mays (Carmona-Salazar et al., 2011). Finalmente, los DRM de neutrófilos bovinos se han recuperado en proporciones entre 5:1 y 10:1 (Nebl et al., 2002), mientras que una relación 3:1 fue suficiente para el aislamiento DRM de las células epiteliales (células MDCK) (Delaunay, Breton, Trugnan \& Maurice, 2008). Finalmente, para $E$. coli se ha reportado que una relación de 8:1 es adecuada para la obtención de DRM a partir de preparaciones de membrana interna (Guzmán-Flores 
et al., 2017).

Por todas estas variables, la obtención de DRM y la interpretación de su análisis bioquímico presenta algunos inconvenientes. Algunas proteínas enriquecidas por estos procedimientos sólo pueden ser obtenidas bajo el uso de ciertos detergentes y en relaciones detergente/proteína específicas, por lo que la identificación de proteínas en DRM no necesariamente deben de ser consideradas una prueba definitiva de la asociación con las balsas lipídicas.

\section{FLOTILINAS COMO MARCADORES DE BALSAS LIPÍDICAS}

Las flotilinas son proteínas recurrentemente identificadas en los DRM obtenidos de diferentes tipos celulares. Estas proteínas pertenecen a una superfamilia que se caracteriza por contener el dominio SPFH (Stomatin, Prohibitin, Flotilin y $H f C / K$ ) o también conocido como dominio PHB (Prohibitin) (Tavernarakis, Driscoll, \& Kyrpides, 1999). Proteínas con este dominio tienen funciones diversas en distintos organismos y tejidos, pero comparten la particularidad de comportarse como proteínas membranales con la capacidad de oligomerizar para formar microdominios. Las células de mamíferos tienen dos flotilinas, denominadas Flotilina-1 (Flo-1) y Flotilina-2 (Flo2), que tienen una identidad de aminoácidos de alrededor del $50 \%$. El dominio SPFH de Flo-1 y Flo-2 constituye la mayor parte del extremo $\mathrm{N}$-terminal, mientras que en el extremo C-terminal se encuentra otro dominio altamente conservado sólo en las familias de las Flotilinas y no en otras proteínas con dominio SPFH (Otto \& Nichols, 2011) (Figura 3a). Este último dominio contiene una región alfa-hélice que participa en la oligomerización para formar homo- y hetero-tetrámeros estables (Figura 3b) (Solís et al., 2007). Curiosamente, Flo1 y Flo-2 carecen de cruces transmembranales, y se asocian a la membrana por modificaciones postraduccionales, particularmente miristoilación y palmitoilación (NeumannGiesen et al., 2004). Como parte integral de las balsas lipídicas, las Flotilinas tienen diversas funciones, como son

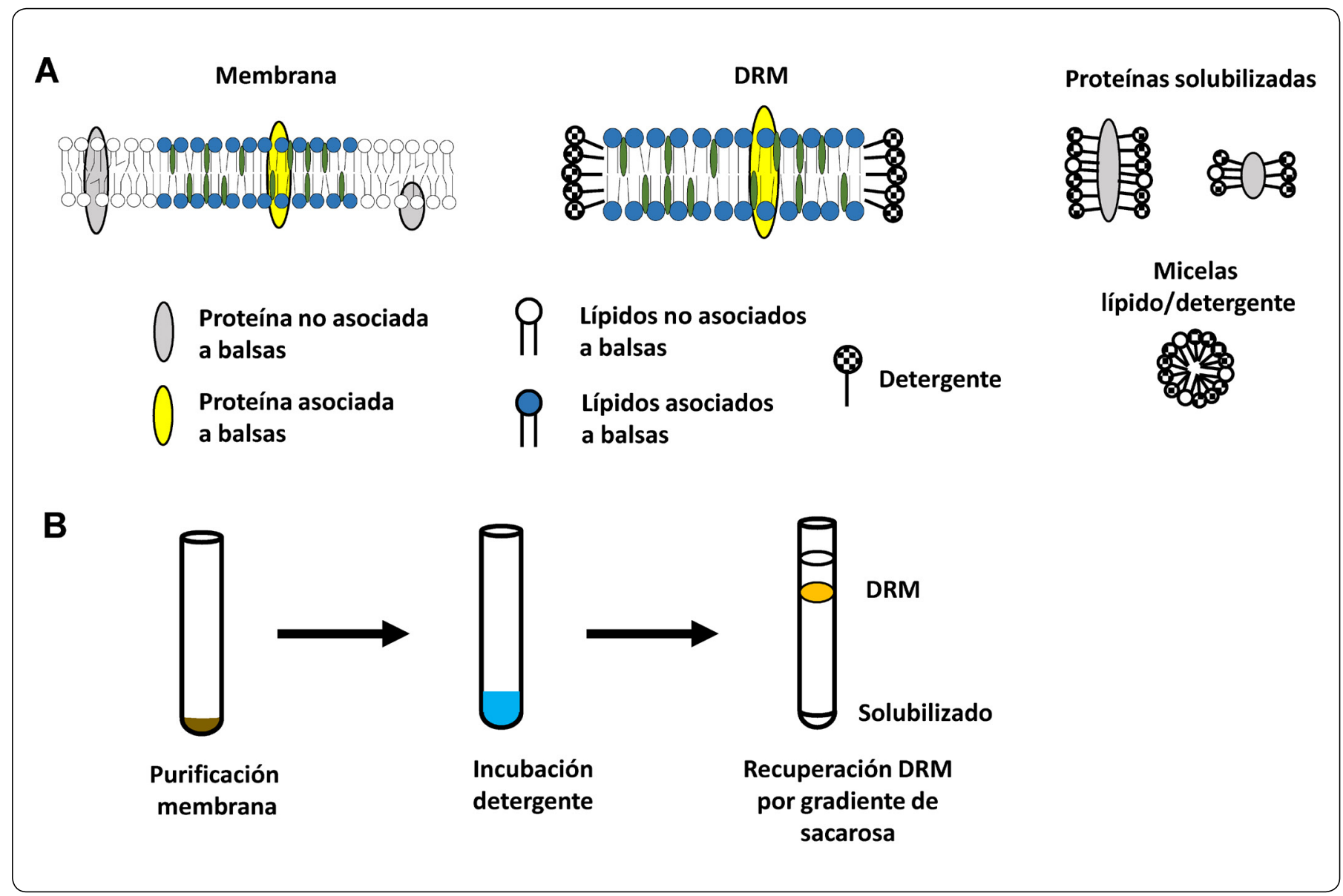

Figura 2. Obtención de DRM. a) Las balsas lipídicas pueden ser extraídas con tratamientos por detergentes, el alto grado de compactación de los componentes permite que los dominios de membrana resistan la solubilización por detergentes. Aquellos componentes que no forman parte de las balsas lipídicas son solubilizados. b) Representación esquemática para la extracción de DRM. Los DRM son obtenidos a partir de preparaciones de membrana y posteriormente por tratamiento de detergente (usualmente Tritón X-100 o CHAPS), luego son recuperados en un gradiente de sacarosa u Optiprep. Debido a la alta relación lípido/proteína los DRM flotan y pueden recuperarse en las fracciones superiores del gradiente. Fuente: elaboración propia. 
A

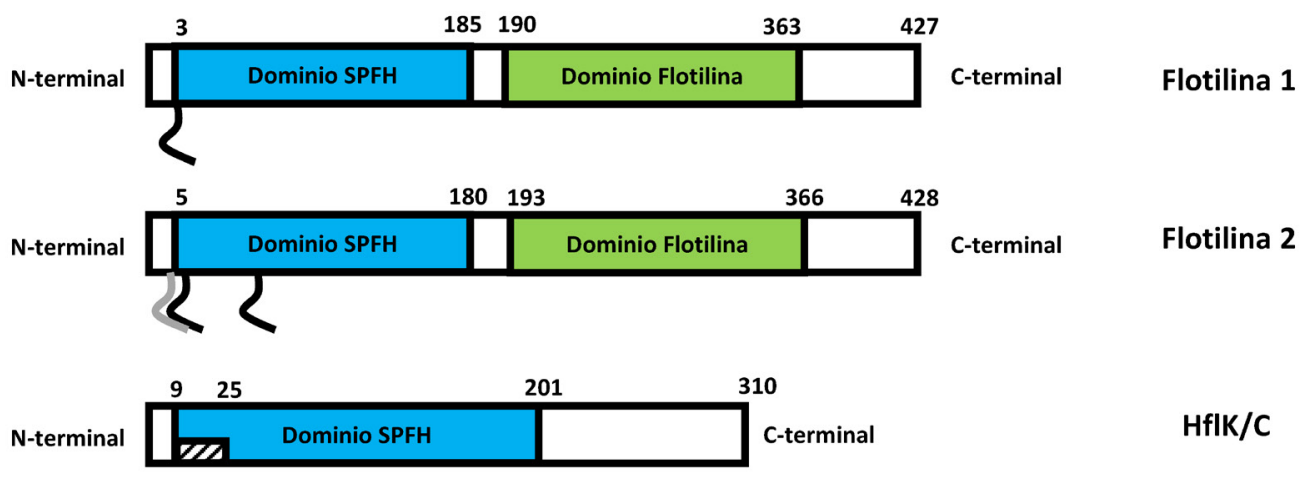

B

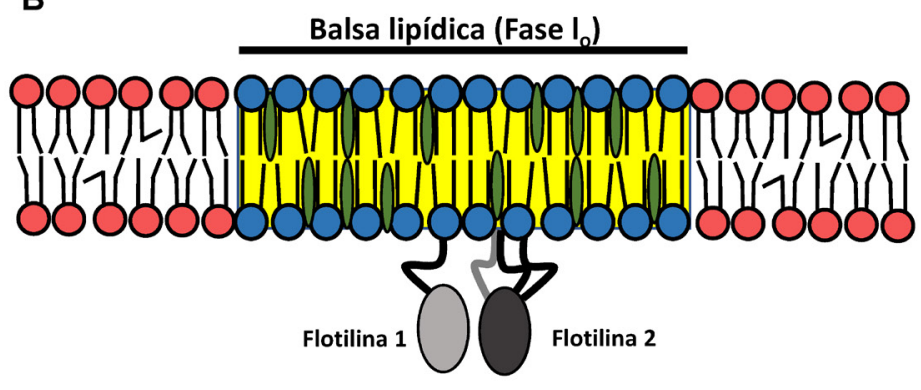

Figura 3. Estructura y componentes de una balsa lipídica. a) Estructura de las proteínas que contienen dominios SPFH, se muestra la ubicación de los dominios SPFH en proteínas eucariontes: Flotilina 1 y 2 , adicionalmente estas proteínas contienen un dominio conservado cerca del C-terminal; por otro lado, las proteínas bacterianas que poseen dominios SPFH (HfIK/C) se asocian a la membrana por cruces transmembranales en lugar de modificaciones postraduccionales y no poseen otro dominio conservado. Los números muestran los límites de los aminoácidos de los dominios. b) Esquema de la composición de una balsa lipídica eucarionte, el microdominio está enriquecido en esteroles y esfingolípidos confiriéndole características similares a una fase $\mathbf{l}_{\mathbf{0}}$, estos dominios de membrana están frecuentemente asociados a proteínas que contienen el dominio SFPH, las cuales son usados como marcadores de balsas lipídicas, las proteínas SPFH pueden estar ancladas a la membrana por modificaciones postraduccionales como la miristoilación o palmitoilación. Fuente: elaboración propia.

participar activamente en la formación y mantenimiento de la propia balsa lipídica, actuar como potenciadores y moduladores de las actividades de las cinasas, además de ser chaperonas y contribuir en la regulación de canales iónicos (Browman, Hoegg \& Robbins, 2007). Debido a que estas proteínas son componentes invariables de las balsas lipídicas, suelen ser usadas como marcadores de estos microdominios membranales.

Además de estar presente en las proteínas de mamíferos Flo1 y Flo-2, el dominio SPFH está ampliamente conservado y distribuido tanto en células eucariontes como procariontes (Browman, Hoegg, \& Robbins, 2007; Tavernarakis, Driscoll \& Kyrpides, 1999). Se estima que más del $90 \%$ de los genomas bacterianos pueden tener por lo menos una proteína con este dominio (Hinderhofer et al., 2009). En el genoma de $E$. coli, se han identificado 4 genes que codifican proteínas que contienen el dominio SPFH, mientras que en B. subtilis dos proteínas, recientemente denominadas FloA y FloT, presentan dicho dominio. En general, a diferencia de Flo-1 y Flo-2, las proteínas con dominio SPFH de bacterias son proteínas integrales de membrana, con uno o más cruces transmembranales (Hinderhofer et al., 2009). A pesar de que las membranas bacterianas carecen de lípidos especializados característicos de balsas lipídicas eucariotas (esfingolípidos y colesterol), se ha demostrado que presentan microdominios membranales funcionales en los que residen las proteínas con dominio SPFH. Al igual que en las células eucariotas, estas proteínas organizan la formación de estos microdominios, reclutando proteínas con diferentes funciones celulares como señalización y secreción (Bach \& Bramkamp, 2013; Mielich-Süss et al., 2017). 


\section{Proteínas asociadas a microdominios Membranales BACTERIANOS}

Al igual que en el estudio de balsas lipídicas eucariontes, la obtención y caracterización de DRM ha sido una de las principales herramientas para el análisis de microdominios membranales bacterianos. Dominios de membrana con características similares a balsas lipídicas de eucariontes, fueron identificados en primera instancia en $B$. subtillis (López \& Kolter, 2010) . Para diferenciarlos de las balsas lipídicas eucariontes, fueron denominados microdominios de membrana funcionales (FMM) (López \& Kolter, 2010). En este estudio, López y Kolter identificaron dos proteínas que contienen el dominio SPFH: FloT (YuaG) y FlotA (YqfA), y observaron que se encuentran localizadas en focos discretos a lo largo de la membrana. Además, encontraron que estas se asocian espacial y funcionalmente con una vía de señalización mediada por un sistema de dos componentes (KinC-Spo0A) que está involucrada en la formación de biopelículas. El análisis proteómico de DRMs obtenidos de membrana plasmática de $B$. subtilis, reveló la presencia de proteínas de señalización (histidina cinasas y quimiorreceptores), proteínas involucradas en la biosíntesis de la pared celular, así como transportadores y proteínas de secreción, además de ambas proteínas con dominio SPFH (Bach \& Bramkamp, 2013; López \& Kolter, 2010). Por otro lado, se ha demostrado que algunas de estas proteínas co-localizan e interactúan directamente con FloT y/o FlotA. Finalmente, se encontró una dependencia funcional de las proteínas con dominios SPFH y la histidina cinasa KinC, así como con la maquinaria Sec de translocación de proteínas (Bach \& Bramkamp, 2013; López \& Kolter, 2010; Schneider, Mielich-Süss, Böhme, \& López, 2015).

En estudios posteriores, se han realizado aproximaciones del contenido de los FMM bacterianos, analizando los DRM obtenidos de membranas de bacterias como Staphylococcus aureus (López \& Kolter, 2010), Borrelia burgdorferi (Toledo, Pérez, Coleman, \& Benach, 2015), Helicobacter pylori y E. coli (resultados propios no publicados). Los resultados indican el enriquecimiento de algunas proteínas con funciones en común en las fracciones de DRM de estos microorganismos, como las proteínas que contienen dominio SPFH que, por lo tanto y al igual que en las balsas lipídicas eucariontes, se utilizan como marcadores de FMM; proteínas con funciones de secreción ( $\mathrm{SecD}, \mathrm{SecY}$ y SecA), componentes estructurales del flagelo (FlaA, FlaB, FlgE), algunas proteasas (FtsH y Htra), cinasas sensoras (KinC, PhoR, ResE, WalK) y síntesis de proteínas (AtpD, AtpG, SA1909-11), entre otras (López \& Koch, 2017). De manera interesante, las proteínas encontradas en los DRM bacterianos tienen funciones similares a las identificadas en DRM eucariontes. Esto permite suponer que los FMM bacterianos, a pesar de que carecen de esfingolípidos y colesterol, son estructuras análogas y funcionalmente semejantes a las balsas lipídicas de las células eucariontes.

\section{CONCLUSIONES}

En los últimos años se ha puesto en manifiesto que dominios similares a las balsas lipídicas de eucariontes están presentes en las membranas bacterianas. Estos dominios están organizados por proteínas con dominio SPFH, y agrupan proteínas con funciones como transducción de señales, transporte, metabolismo energético, división celular, metabolismo de la pared celular, entre otras. Además, en muchos casos la integridad de los FMM bacterianos afecta la expresión de factores de virulencia.

Si bien se ha avanzado en el análisis proteómico y funcional de los FMM bacterianos, la composición lipídica de estos microdominios sigue siendo una incógnita. La falta de esteroles como el colesterol en la composición lipídica de la mayoría de las membranas bacterianas, plantea el interrogante de qué moléculas pueden reemplazar su función en microdominios membranales. Se ha propuesto que hopanoides y carotenoides, presentes en las membranas de bacterias como B. subtilis y $S$. aureus, podrían reemplazar funcionalmente al colesterol en los microdominios de estos microorganismos. Sin embargo, bacterias como E. coli carecen de estas formas lipídicas. Por lo tanto, los esfuerzos para identificar las especies de lípidos esenciales para la formación de estos dominios membranales tanto en E. coli como en otras bacterias han cobrado gran relevancia.

Una de las técnicas más empleadas para estudiar el contenido de los dominios de membrana son los DRM. El análisis de los DRM en membranas bacterianas ha permitido identificar proteínas con funciones similares a los reportados en balsas lipídicas eucariontes, lo que sugiere que los FMM poseen funciones de regulación similar a sus contrapartes eucariontes. A pesar de que los DRM no necesariamente reflejan el contenido real de las balsas lipídicas, la extracción por detergente sigue siendo una de las primeras aproximaciones para determinar el contenido de las balsas lipídicas y de los microdominios membranales bacterianos.

\section{Agradecimientos}

Los autores agradecen a la Dirección General de Asuntos del Personal Académico (DGAPA) de la UNAM, por el apoyo financiero a los proyectos IN209918 y IN208718. Agradecemos a la M en C. Claudia Rodríguez Rangel por el apoyo técnico brindado. José Enrique Guzmán Flores agradece al CONACYT por la beca de doctorado otorgada.

\section{REFERENCIAS}

Alfalah, M., Wetzel, G., Fischer, I., Busche, R., Sterchi, E. E., Zimmer, K.-P., Sallman, H.-P., \& Naim, H. Y. (2005). A Novel Type of Detergent-resistant Membranes May Contribute to an Early Protein Sorting Event in Epithelial Cells. Journal of Biological Chemistry, 280(52), 42636- 
42643. https://doi.org/10.1074/JBC.M505924200

An, D., Na, C., Bielawski, J., Hannun, Y. A., \& Kasper, D. L. (2011). Membrane sphingolipids as essential molecular signals for Bacteroides survival in the intestine. Proceedings of the National Academy of Sciences of the United States of America, 108 (Suppl 1), 4666-4671. https://doi.org/10.1073/pnas.1001501107

Babiychuk, E. B., \& Draeger, A. (2006). Biochemical characterization of detergent-resistant membranes: a systematic approach. The Biochemical Journal, 397(3), 407-416. https://doi.org/10.1042/BJ20060056

Bach, J. N., \& Bramkamp, M. (2013). Flotillins functionally organize the bacterial membrane. Molecular Microbiology, 88(6), 1205-1217. https://doi.org/10.1111/ mmi. 12252

Bernal, P., Muñoz-Rojas, J., Hurtado, A., Ramos, J. L., \& Segura, A. (2007). A Pseudomonas putida cardiolipin synthesis mutant exhibits increased sensitivity to drugs related to transport functionality. Environmental Microbiology, 9(5), 1135-1145. https://doi.org/10.1111/ j.1462-2920.2006.01236.x

Borner, G. H. H., Sherrier, D. J., Weimar, T., Michaelson, L. V, Hawkins, N. D., Macaskill, A., Napier, J. A., Beale, M. H., Lilley, K. S., \& Dupree, P. (2005). Analysis of detergentresistant membranes in Arabidopsis. Evidence for plasma membrane lipid rafts. Plant Physiology, 137(1), 104-116. https://doi.org/10.1104/pp.104.053041

Browman, D. T., Hoegg, M. B., \& Robbins, S. M. (2007, August). The SPFH domain-containing proteins: more than lipid raft markers. Trends in Cell Biology, 17(8), 394-402. https://doi.org/10.1016/j.tcb.2007.06.005

Brown, D. A. (2006). Lipid Rafts, Detergent-Resistant Membranes, and Raft Targeting Signals. Physiology, 21(6), 430-439. https://doi.org/10.1152/physiol.00032.2006

Brown, D. A., \& London, E. (1998). Structure and origin of ordered lipid domains in biological membranes. Journal of Membrane Biology, 164(2), 103-114. https://doi. org/10.1007/s002329900397

Brown, D. A., \& Rose, J. K. (1992). Sorting of GPI-anchored proteins to glycolipid-enriched membrane subdomains during transport to the apical cell surface. Cell, 68(3), 533-544. https://doi.org/10.1016/0092-8674(92)90189-J

Carmona-Salazar, L., El Hafidi, M., Enríquez-Arredondo, C., Vázquez-Vázquez, C., González De La Vara, L. E., \& Gavilanes-Ruiz, M. (2011). Isolation of detergentresistant membranes from plant photosynthetic and nonphotosynthetic tissues. Analytical Biochemistry, 417(2), 220-227. https://doi.org/10.1016/j.ab.2011.05.044

Clejan, S., Krulwich, T. A., Mondrus, K. R., \& Seto-Young, D. (1986). Membrane lipid composition of obligately and facultatively alkalophilic strains of Bacillus spp. Journal of Bacteriology, 168(1), 334-340. https://doi. org/10.1128/jb.168.1.334-340.1986

Cronan, J. E. (2003). Bacterial Membrane Lipids: Where Do We
Stand? Annual Review of Microbiology, 57(1), 203-224. https://doi.org/10.1146/annurev.micro.57.030502.090851

Daley, D. O., Rapp, M., Granseth, E., Melén, K., Drew, D., \& von Heijne, G. (2005). Global topology analysis of the Escherichia coli inner membrane proteome. Science (New York, N.Y.), 308(5726), 1321-1323. https://doi. org/10.1126/science. 1109730

Delaunay, J. L., Breton, M., Trugnan, G., \& Maurice, M. (2008). Differential solubilization of inner plasma membrane leaflet components by Lubrol WX and Triton X-100. Biochimica et Biophysica Acta - Biomembranes, 1778(1), 105-112. https://doi.org/10.1016/j.bbamem.2007.09.017

Deol, S. S., Bond, P. J., Domene, C., \& Sansom, M. S. P. (2004). Lipid-protein interactions of integral membrane proteins: A comparative simulation study. Biophysical Journal, 87(6), 3737-3749. https://doi.org/10.1529/ biophysj.104.048397

Fishov, I., \& Woldringh, C. L. (1999). Visualization of membrane domains in Escherichia coli. Molecular Microbiology, 32(6), 1166-1172. https://doi.org/10.1046/ j.1365-2958.1999.01425.x

Frye, L. D., \& Edidin, M. (1970). The Rapid Intermixing of Cell Surface Antigens After Formation of MouseHuman Heterokaryons. Journal of Cell Science, 7(2), 319-335. Retrieved from http://www.ncbi.nlm.nih.gov/ pubmed/4098863

Gilleland, H. E., \& Lyle, R. D. (1979). Chemical alterations in cell envelopes of polymyxin-resistant Pseudomonas aeruginosa isolates. Journal of Bacteriology, 138(3), 839-845. Retrieved from http://www.ncbi.nlm.nih.gov/ pubmed/6271731

Guzmán-Flores, J. E., Álvarez, A. F., Poggio, S., GavilanesRuiz, M., \& Georgellis, D. (2017). Isolation of detergentresistant membranes (DRMs) from Escherichia coli. Analytical Biochemistry, 518(1), 1-8. https:/doi. org/10.1016/j.ab.2016.10.025

Hinderhofer, M., Walker, C. A., Friemel, A., Stuermer, C. A., Möller, H. M., \& Reuter, A. (2009). Evolution of prokaryotic SPFH proteins. BMC Evolutionary Biology, 9(10), 1-18. https://doi.org/10.1186/1471-2148-9-10

Hutton, M. L., D’Costa, K., Rossiter, A. E., Wang, L., Turner, L., Steer, D. L., Masters, S. L., Croker, B. A., KaparakisLiaskos, M., \& Ferrero, R. L. (2017). A Helicobacter pylori Homolog of Eukaryotic Flotillin Is Involved in Cholesterol Accumulation, Epithelial Cell Responses and Host Colonization. Frontiers in Cellular and Infection Microbiology, 7, 219. https://doi.org/10.3389/ fcimb.2017.00219

Kamio, Y., \& Nikaido, H. (1976). Outer membrane of Salmonella typhimurium: accessibility of phospholipid head groups to phospholipase $\mathrm{C}$ and cyanogen bromide activated dextran in the external medium. Biochemistry, 15(12), 2561-2570. https://doi.org/10.1021/bi00657a012 Kawai, F., Shoda, M., Harashima, R., Sadaie, Y., Hara, H., \& 
Matsumoto, K. (2004). Cardiolipin Domains in Bacillus subtilis Marburg Membranes. Journal of Bacteriology, 186(5), 1475-1483. https://doi.org/10.1128/ JB.186.5.1475-1483.2004

Krogh, A., Larsson, B., von Heijne, G., \& Sonnhammer, E. L. . (2001). Predicting transmembrane protein topology with a hidden markov model: application to complete genomes. Journal of Molecular Biology, 305(3), 567580. https://doi.org/10.1006/JMBI.2000.4315

LaRocca, T. J., Pathak, P., Chiantia, S., Toledo, A., Silvius, J. R., Benach, J. L., \& London, E. (2013). Proving Lipid Rafts Exist: Membrane Domains in the Prokaryote Borrelia burgdorferi Have the Same Properties as Eukaryotic Lipid Rafts. PLoS Pathogens, 9(5), e1003353. https://doi.org/10.1371/journal.ppat.1003353

Lee, A. G. (2003). Lipid-protein interactions in biological membranes: A structural perspective. Biochimica et Biophysica Acta - Biomembranes, 1612(1), 1-40. https:// doi.org/10.1016/S0005-2736(03)00056-7

Lisanti, M. P., \& Rodríguez-Boulan, E. (1990). Glycophospholipid membrane anchoring provides clues to the mechanism of protein sorting in polarized epithelial cells. Trends in Biochemical Sciences, 15(3), 113-118. https://doi.org/10.1016/0968-0004(90)90195-H

López, D., \& Koch, G. (2017). Exploring functional membrane microdomains in bacteria: an overview. Current Opinion in Microbiology, 36, 76-84. https://doi.org/10.1016/J. MIB.2017.02.001

López, D., \& Kolter, R. (2010). Functional microdomains in bacterial membranes. Genes and Development, 24(17), 1893-1902. https://doi.org/10.1101/gad.1945010

Luirink, J., Yu,Z., Wagner, S., \& de Gier, J.-W.(2012). Biogenesis of inner membrane proteins in Escherichia coli. Biochimica et Biophysica Acta (BBA) - Bioenergetics, 1817(6), 965976. https://doi.org/10.1016/J.BBABIO.2011.12.006

Macdonald, J. L., \& Pike, L. J. (2005). A simplified method for the preparation of detergent-free lipid rafts. Journal of Lipid Research, 46(5), 1061-1067. https://doi. org/10.1194/jlr.D400041-JLR200

Magee, A. I., \& Parmryd, I. (2003). Detergent-resistant membranes and the protein composition of lipid rafts. Genome Biology, 4:234. https://doi.org/10.1186/gb2003-4-11-234

Maloney, E., Lun, S., Stankowska, D., Guo, H., Rajagoapalan, M., Bishai, W. R., \& Madiraju, M. V. (2011). Alterations in phospholipid catabolism in Mycobacterium tuberculosis lysX mutant. Frontiers in Microbiology, 2(FEB), 1-19. https://doi.org/10.3389/fmicb.2011.00019

Mazzone, A., Tietz, P., Jefferson, J., Pagano, R., \& LaRusso, N. F. (2006). Isolation and characterization of lipid microdomains from apical and basolateral plasma membranes of rat hepatocytes. Hepatology, 43(2), 287296. https://doi.org/10.1002/hep.21039

Mielich-Süss, B., Wagner, R. M., Mietrach, N., Hertlein, T.,
Marincola, G., Ohlsen, K., Geibel, S., \& López, D. (2017). Flotillin scaffold activity contributes to type VII secretion system assembly in Staphylococcus aureus. PLoS Pathogens, 13(11), e1006728. https://doi.org/10.1371/ journal.ppat.1006728

Mileykovskaya, E., \& Dowhan, W. (2000). Visualization of phospholipid domains in Escherichia coli by using the cardiolipin-specific fluorescent dye 10-N-nonyl acridine orange. Journal of Bacteriology, 182(4), 1172-1175. https://doi.org/10.1128/JB.182.4.1172-1175.2000

Mongrand, S., Morel, J., Laroche, J., Claverol, S., Carde, J. P., Hartmann, M. A., Bonneu, M., Simon-Plas, F., Lessire, R., \& Bessoule, J. J. (2004). Lipid rafts in higher plant cells: Purification and characterization of triton X-100insoluble microdomains from tobacco plasma membrane. Journal of Biological Chemistry, 279(35), 36277-36286. https://doi.org/10.1074/jbc.M403440200

Nebl, T., Pestonjamasp, K. N., Leszyk, J. D., Crowley, J. L., Oh, S. W., \& Luna, E. J. (2002). Proteomic analysis of a detergent-resistant membrane skeleton from neutrophil plasma membranes. The Journal of Biological Chemistry, 277(45), 43399-43409. https://doi.org/10.1074/jbc. M205386200

Neumann-Giesen, C., Falkenbach, B., Beicht, P., Claasen, S., Lüers, G., Stuermer, C. A. O., Herzog, V., \& Tikkanen, R. (2004). Membrane and raft association of reggie-1/ flotillin-2: role of myristoylation, palmitoylation and oligomerization and induction of filopodia by overexpression. The Biochemical Journal, 378(2), 509518. https://doi.org/10.1042/BJ20031100

Otto, G. P., \& Nichols, B. J. (2011). The roles of flotillin microdomains - endocytosis and beyond. Journal of Cell Science, 124(23), 3933-3940. https://doi.org/10.1242/ jcs.092015

Papanastasiou, M., Orfanoudaki, G., Koukaki, M., Kountourakis, N., Sardis, M. F., Aivaliotis, M., Karamanou, S., \& Economou, A. (2013). The Escherichia coli peripheral inner membrane proteome. Molecular \& Cellular Proteomics : MCP, 12(3), 599-610. https://doi. org/10.1074/mcp.M112.024711

Pike, L. J. (2006). Rafts defined: a report on the Keystone Symposium on Lipid Rafts and Cell Function. Journal of Lipid Research, 47(7), 1597-1598. https://doi. org/10.1194/jlr.E600002-JLR200

Renner, L. D., \& Weibel, D. B. (2011). Cardiolipin microdomains localize to negatively curved regions of Escherichia coli membranes. Proceedings of the National Academy of Sciences of the United States of America, 108(15), 6264-6269. https://doi.org/10.1073/ pnas. 1015757108

Rothman, J. E., \& Kennedy, E. P. (1977). Symmetrical distribution of phospholipids in the membrane of Bacillus megaterium. Journal of Molecular Biology, 110(3), 603618. https://doi.org/10.1016/S0022-2836(77)80114-9 
Schneider, J., Mielich-Süss, B., Böhme, R., \& López, D. (2015). In vivo characterization of the scaffold activity of flotillin on the membrane kinase KinC of Bacillus subtilis. Microbiology, 161(9), 1871-1887. https://doi. org/10.1099/mic.0.000137

Schuck, S., Honsho, M., Ekroos, K., Shevchenko, A., \& Simons, K. (2003). Resistance of cell membranes to different detergents. Proceedings of the National Academy of Sciences of the United States of America, 100(10), 5795-5800. https://doi.org/10.1073/pnas.0631579100

Silhavy, T. J., Kahne, D., \& Walker, S. (2010). The bacterial cell envelope. Cold Spring Harbor Perspectives in Biology, 2(5), a000414. https://doi.org/10.1101/ cshperspect.a000414

Simons, K., \& Ikonen, E. (1997). Functional rafts in cell membranes. Nature, 387(6633), 569-572. https://doi. org $/ 10.1038 / 42408$

Simons, K., \& Van Meer, G. (1988). Lipid sorting in epithelial cells. Biochemistry, 27(17), 6197-6202. https://doi. org/10.1021/bi00417a001

Singer, S. J. J., \& Nicolson, G. L. L. (1972). The fluid mosaic model of the structure of cell membranes. Science, 175(4023), 720-731. https://doi.org/10.1126/ science. 175.4023 .720

Siontorou, C., Nikoleli, G.-P., Nikolelis, D., \& Karapetis, S. (2017). Artificial Lipid Membranes: Past, Present, and Future. Membranes, 7(3), 38. https://doi.org/10.3390/ membranes 7030038

Sohlenkamp, C., \& Geiger, O. (2016). Bacterial membrane lipids: Diversity in structures and pathways. (F. Narberhaus, Ed.), FEMS Microbiology Reviews. Oxford University Press. https://doi.org/10.1093/femsre/fuv008
Solís, G. P., Hoegg, M., Munderloh, C., Schrock, Y., MalagaTrillo, E., Rivera-Milla, E., \& Stuermer, C. A. O. (2007). Reggie/flotillin proteins are organized into stable tetramers in membrane microdomains. The Biochemical Journal, 403(2), 313-322. https://doi.org/10.1042/BJ20061686

Somani, V. K., Aggarwal, S., Singh, D., Prasad, T., \& Bhatnagar, R. (2016). Identification of Novel Raft Marker Protein, FlotP in Bacillus anthracis. Frontiers in Microbiology, 7, 169. https://doi.org/10.3389/fmicb.2016.00169

Stoops, E. H., \& Caplan, M. J. (2014). Trafficking to the Apical and Basolateral Membranes in Polarized Epithelial Cells. Journal of the American Society of Nephrology, 25(7), 1375-1386. https://doi.org/10.1681/ASN.2013080883

Tavernarakis, N., Driscoll, M., \& Kyrpides, N. C. (1999). The SPFH domain: implicated in regulating targeted protein turnover in stomatins and other membrane-associated proteins. Trends in Biochemical Sciences, 24(11), 425427. https://doi.org/10.1016/S0968-0004(99)01467-X

Toledo, A., Pérez, A., Coleman, J. L., \& Benach, J. L. (2015). The lipid raft proteome of Borrelia burgdorferi. Proteomics, 15(21), 3662-3675. https://doi.org/10.1002/ pmic. 201500093

van Meer, G., Voelker, D. R., \& Feigenson, G. W. (2008). Membrane lipids: where they are and how they behave. Nature Reviews Molecular Cell Biology, 9(2), 112-124. https://doi.org/10.1038/nrm2330

Williamson, R., Thompson, A. J., Abu, M., Hye, A., Usardi, A., Lynham, S., Anderton, B. H., \& Hanger, D. P. (2010). Isolation of detergent resistant microdomains from cultured neurons: detergent dependent alterations in protein composition. BMC Neuroscience, 11, 120. https:// doi.org/10.1186/1471-2202-11-120. 